\title{
Pelatihan Manajemen Pemasaran Berbasis Website pada Usaha Kue Wecakee Denpasar
}

\author{
Ni Putu Nanik Hendayanti ${ }^{1}$, Kadek Dwi Pradnyani Novianti ${ }^{2}$, Luh Putu Safitri Pratiwi ${ }^{3}$ \\ nanik@stikom-bali.ac.id', novianti@stikom-bali.ac.id², putu_safitri@stikom- \\ bali.ac.id ${ }^{3}$

\section{1,2,3 ITB STIKOM BALI}

\section{Article History:}

Received: 18-06-2021

Revised: 29-06-2021

Accepted: 22-07-2021
Keywords: Marketing management, website

\begin{abstract}
The development of the home industry, especially in Bali, is currently a very promising business for the perpetrators. Business growth in Bali reaches 4\% per year. Wecakee Denpasar is one of the home industries engaged in cake making. This cake-making business only has a homestore and is run by the owner, I Ketut Gede Andrayuga. Wecakee Denpasar produces various kinds of cakes such as cakes, pastries, and sponge. So far, the marketing system carried out by Wecakee Denpasar is word of mouth and is usually based on the friend's relationship with the owner. Seeing the condition of marketing management like this, it causes an uncertain amount of production every day. Based on the description above, the priority problem experienced by partners is marketing management which is still done conventionally, therefore the objectives of this community service activity at Wecakee Denpasar are: Creating a Wecakee Denpasar marketing website. The results of this service, namely the evaluation using a questionnaire, obtained the results of the Very Good index category with an index value of $92.5 \%$.
\end{abstract}

\section{Pendahuluan}

Perkembangan industri rumah tangga terutama di Bali saat ini menjadi usaha yang sangat menjanjikan bagi para pelakunya. Pertumbuhan usaha di Bali mencapai $4 \%$ per tahun. Selain itu, jumlah wirausaha di Bali meningkat sekitar $7 \%$ melebihi dari kondisi nasional sekitar 2\% (Pranishita, 2019). Sebagai contoh adalah industri rumah tangga yang bergerak di bidang pembuatan kue. Usaha ini merupakan usaha yang profitable karena tidak memerlukan modal yang terlampaui besar dan dapat dijalankan pada lokasi dengan ukuran yang kecil seperti dapur rumah. Selain itu, usaha pembuatan kue ini memerlukan peralatan yang tidak terlalu besar. Salah satu usaha pembuatan kue yaitu Wecakee Denpasar. Usaha pembuatan kue ini hanya memiliki homestore yang berlokasi di Jalan Hayam Wuruk Denpasar dan dijalankan oleh pemiliknya bernama I Ketut Gede Andrayuga. Wecakee Denpasar memproduksi berbagai macam kue seperti cake, roti kering, dan bolu. Adapun produk yang diproduksi oleh Wecakee Denpasar dapat dilihat pada Gambar 1 dibawah ini. 


\section{ADMA}

Gurnal Pengabdian dan Pemberdayaan Masyarakat
Tahun, Vol.2, No.1, pp.45-52

Doi: 10.30812/adma.v2i1.1287
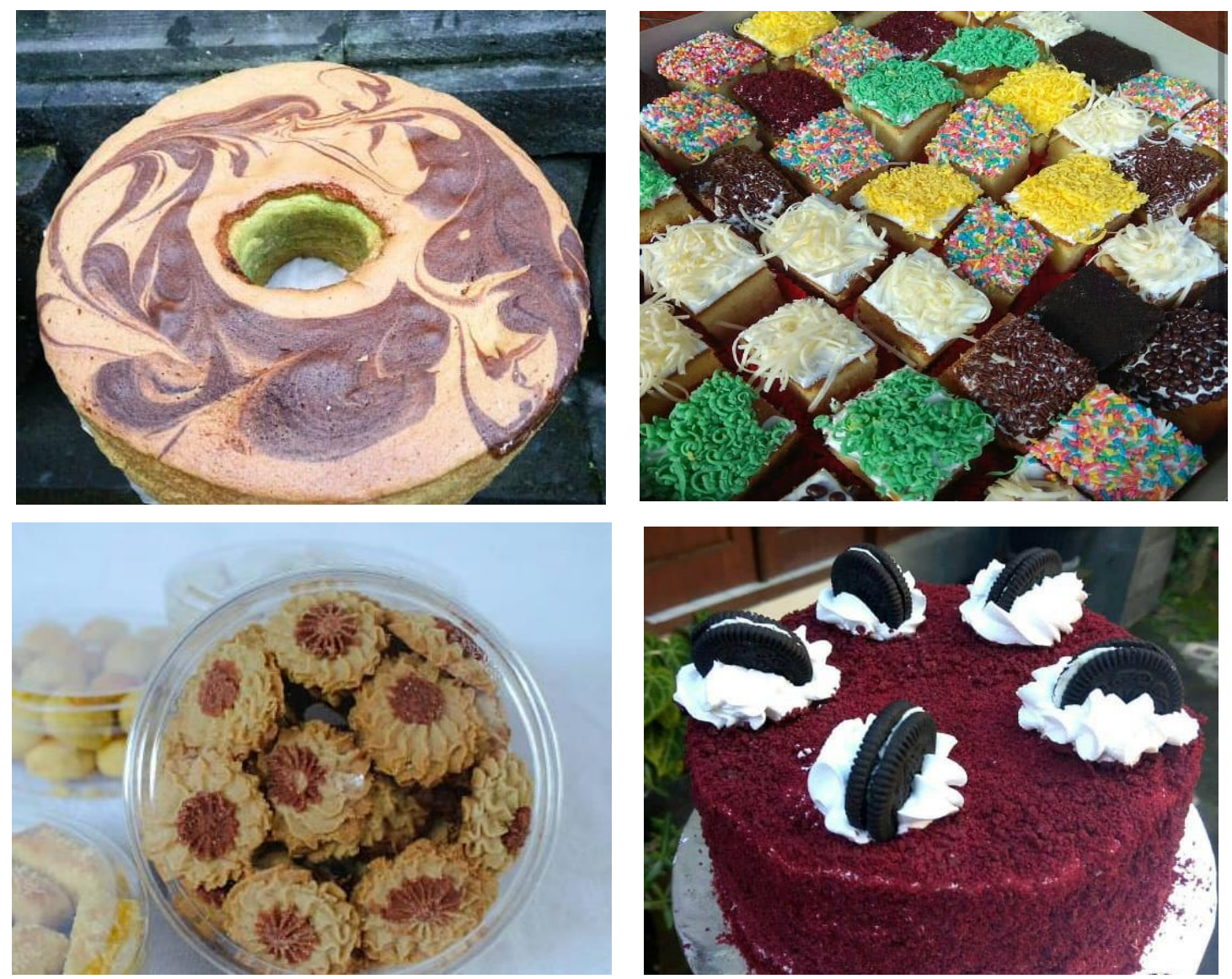

Gambar 1. Produk Wecakee Denpasar

Wecakee Denpasar menjalankan usahanya berdasarkan pesanan dari konsumennya. Apabila konsumen ingin memesan kue, konsumen dapat melakukan pemesanan melalui pesan whatsapp ke pemilik Wecakee Denpasar. Selama ini sistem pemasaran yang dilakukan oleh Wecakee Denpasar adalah dari mulut ke mulut dan biasanya berdasarkan hubungan pertemanan pemiliknya. Melihat kondisi manajemen pemasaran seperti ini, menyebabkan jumlah produksi yang tidak menentu setiap harinya. Setiap harinya Wecakee Denpasar memproduksi paling banyak 5 item kue dan jumlah produksi kue akan banyak hanya pada hari-hari tertentu seperi perayaan hari raya keagamaan. Melihat kondisi produksi seperti ini, Wecakee Denpasar perlu untuk memperluas jangkauan pasar yang dimilikinya sehingga jumlah produksi kue yang dihasilkan dapat konsisten bahkan meningkat.

Menurut Kotler \& Amstrong (2012), menjelaskan bahwa pemasaran adalah proses sosial dan manajerial dimana individu dan kelompok memenuhi kebutuhan dan keinginan mereka dengan menciptakan, menawarkan, dan bertukar sesuatu yang bernilai dengan pihak lain. Dalam upaya untuk menyelesaikan permasalahan yang dihadapi oleh Wecakee Denpasar, diperlukan solusi yang tepat sehingga target yang diinginkan dapat tercapai. Solusi yang dapat dilakukan untuk hal tersebut adalah dengan implementasi teknologi untuk 


\section{ADMA}

Jurnal Pengabdian dan Pemberdayaan Masyarakat
Tahun, Vol.2, No.1, pp.45-52

Doi: $10.30812 / a d m a . v 2 i 1.1287$

melakukan pemasaran. Maka dari itu, akan dilaksanakan pengabdian masyarakat berupa pelatihan untuk manajemen pemasaran produk Wecakee Denpasar menggunakan website. Manajemen pemasaran produk Wecakee Denpasar berbasis website ini nantinya berisi fitur agar pelanggan dapat melihat katalog produk dan melakukan pemesanan produk Wecakee Denpasar. Strategi pemasaran dengan menggunakan website dapat menjadi salah satu cara untuk memperkenalkan perusahaan di mata masyarakat.

Menurut Nielsen (2003) interface website harus memenuhi lima syarat untuk mencapai tingkat usability yang ideal, antara lain: (1) mudah untuk dipelajari - letakkan isi yang paling penting pada bagian atas halaman, agar pengunjung mendapatkannya dengan cepat. (2) efisien dalam penggunaan - jangan menggunakan link yang terlalu banyak, sediakan seperlunya dan hantarkan pengunjung mencapai informasi yang diperlukan dengan cepat dan mudah. (3) mudah untuk diingat - situs jangan terlalu banyak melakukan perubahan yang terlalu mencolok khususnya pada navigasi. (4) tingkat kesalahan rendah hindari link yang tidak berfungsi (broken link) atau halaman yang masihdalam proses pembuatan (under construction). (5) kepuasan pengguna - kepuasan adalah hal yang penting untuk diperhatikan untuk keberlangsungan website.

E-marketing adalah suatu proses membangun dan mempertahankan hubungan dengan pelanggan melalui suatu kegiatan online untuk memberikan fasilitas pertukaran ide, produk dan pelayanan untuk memenuhi keinginan dari kedua belah pihak (Rafi et al, 2003, p.4). Tujuan dari aplikasi website e-marketing yang menggabungkan beragam teknologi informasi adalah untuk: melakukan perubahan strategi pemasaran untuk menambah nilai pelanggan melalui segmentasi; menciptakan perubahan untuk memuaskan konsumen; meningkatkan perencanaan dan mematangkan konsep sehingga mempermudah promosi dan lain sebagainya (Chaffey, 2000).

\section{Metode}

Sebagai kegiatan awal akan dilakukan sosialisasi kegiatan kepada mitra berkaitan dengan kegiatan pengabdian masyarakat yang akan dilakukan dan dengan tidak melupakan protokol kesehatan. Dalam sosialisasi akan diberitahukan target dan tujuan kegiatan kepada Mitra. Dimana kegiatan pengabdian ini yang akan diselenggarakan secara daring kepada mitra. Persiapan pelatihan dilakukan terkait dengan materi dan website yang akan diberikan kepada mitra. Disamping itu juga, akan dilakukan pelatihan untuk menggunakan website pemasaran pada Wecakee Denpasar. Mulai dari pengenalan fitur sampai dengan penggunaan fitur pada website kepada mitra.

Evaluasi kegiatan akan dilaksanakan setelah mitra menggunakan website yang diberikan untuk melihat tingkat pemahaman mitra dalam menggunakan website. Kegiatan terakhir yaitu pelaksanaan pendampingan yang akan dilaksanakan sesuai dengan waktu 
yang disepakati dengan mitra yang betujuan untuk memaksimalkan keahlian mitra dalam penggunaan website. Adapun rangkaian kegiatan yang akan dilakukan dapat dilihat pada Gambar 2 di bawah ini:

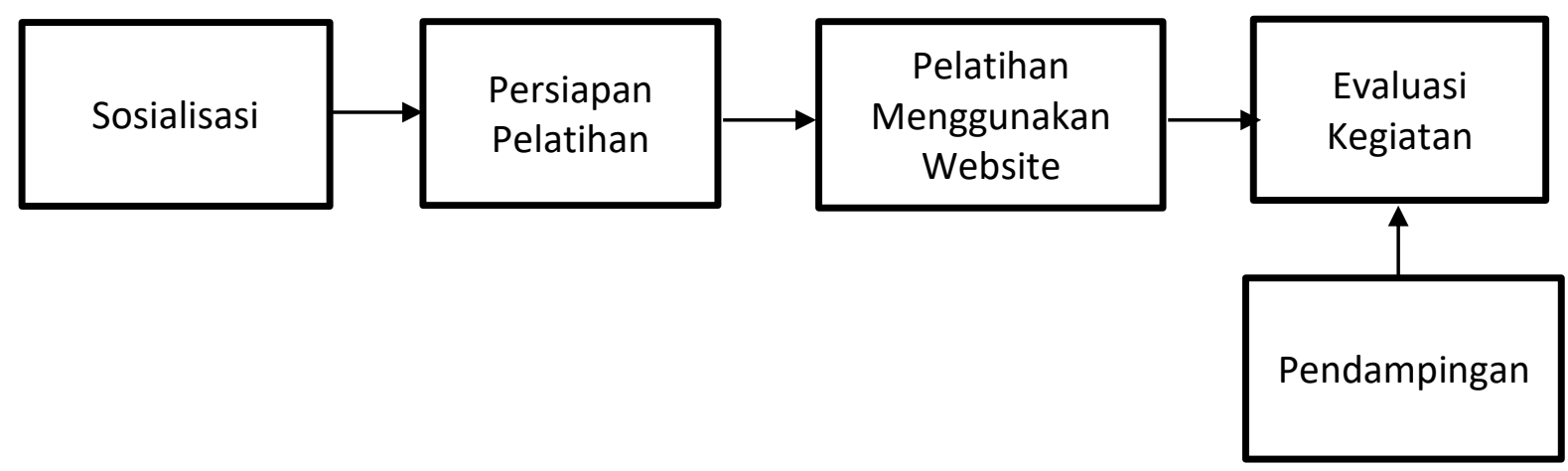

Gambar 2. Rangkaian kegiatan pengabdian

\section{Pembahasan}

Berikut akan dijabarkan uraian pelaksanaan kegiatan berdasarkan susunan acara yang telah dibuat.

1) Pengenalan dan Sosialisasi Program

Pada tahapan ini dilakukan pengenalan serta deskripsi kegiatan-kegiatan yang akan dilakukan pada pengabdian masyarakat.

2) Pemaparan Tentang Manfaat Website

Kegiatan pemaparan tentang manfaat website ini bertujuan untuk memberikan pemahaman kepada mitra mengenai bagaimana website dapat membantu kegiatan pemasaran serta memperluas cakupan wilayah pemasaran dari toku kue Wecakee ini.

3) Pelatihan Menggunakan Website

Media pemasaran adalah perangkat, wadah, tempat, atau perantara untuk melakukan sebuah kegiatan pemasaran dan berfungsi untuk membantu kebutuhan bisnis dan mempercepat proses kegiatan pemasaran. Teknik ini menggunakan perangkat digital dan dan beberapa aplikasi pendukung, dan umumnya, bersifat open source.

Salah satu media yang sering digunakan untuk mengembangkan bisnis pemasaran sendiri adalah dengan menggunakan bantuan website. Di era digital, penggunaan dari website dan perangkat mobile terus meningkat karena berbagai kemudahan yang diberikan dari sisi tampilan, dan penyampaian informasi yang cepat, akurat, dan tepat. Manfaat Website bagi Toko Kue Wecakee adalah sebagai berikut:

a) Sarana untuk melakukan pemasaran melalui jaringan internet

Perkembangan Internet semakin meningkat dari waktu ke waktu. Media website menjadi pilihan yang tepat untuk menjadi sarana media pemasaran seperti 


\section{ADMA}

Gurnal Pengabdian dan Pemberdayaan Masyarakat
Tahun, Vol.2, No.1, pp.45-52

Doi: 10.30812/adma.v2i1.1287

melakukan kegiatan promosi, dan iklan produk layanan yang dimiliki. Toko Ku Wecakee memanfaatkan website sebagai salah satu sarana untuk mempromosikan produk atau jasa untuk meraih keuntungan mendapatkan jaringan yang luas dan banyak.

Website sendiri memiliki jangkauan waktu dan ruang yang tak terbatas dengan penyampaian informasi yang sangat jelas sehingga produk yang terjual dapat diproses dengan sangat mudah.

b) Mengenalkan brand produk dari sebuah perusahaan

Produk Kue Wecakee dapat mulai mempromosikan produknya melalui website yang telah dibangun. Harapannya adalah cakupan wilayah target semakin luas.

c) Memudahkan pelaku usaha menjalin kerjasama dengan konsumen

Website mempunyai fitur seperti kontak email, telepon, dan media sosial lainnya. Sehingga, apabila komunikasi dapat terjaga dengan baik, maka loyalitas akan meningkat. Selaras dengan Toko Kue Wecakee yang akan meningkat dari penerapan media marketing pada bisnis ini.

Adapun pemaparan mengenai wesite serta pelatihan yang dllakukan adalah sebagai berikut.

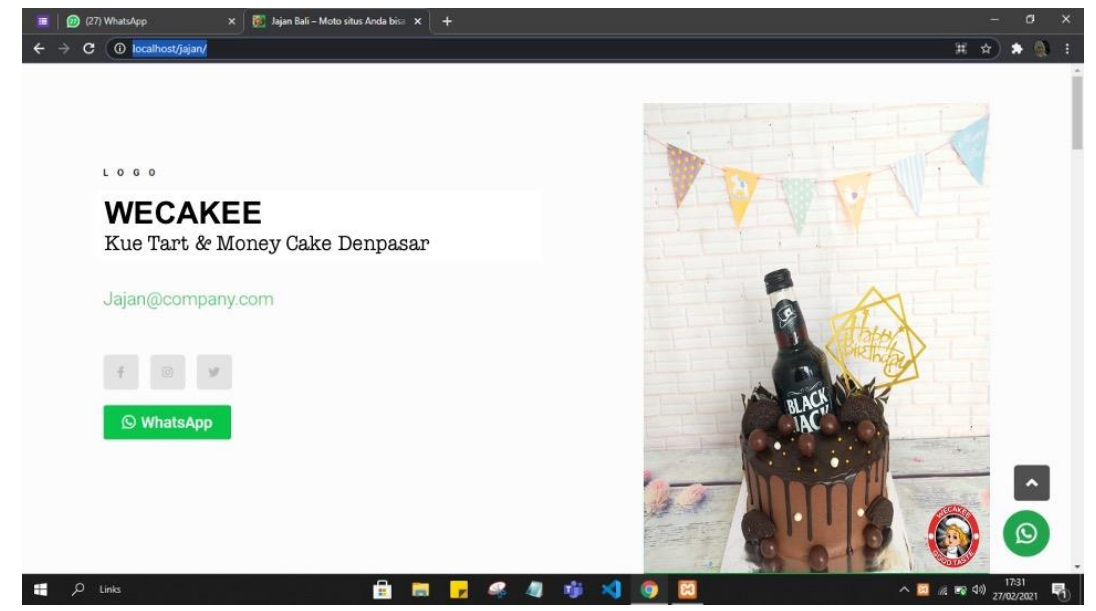

Gambar 3. Beranda Wecakee

Halaman ini menampilkan profil dari toko kue wecakee. Profil menampilkan kontak atau cara menghubungi toko kue ini. Kontak dapat dilakukan melalui Facebook, Instagram, Twitter dan Whatsapp. 


\section{ADMA}

Gurnal Pengabdian dan Pemberdayaan Masyarakat
Tahun, Vol.2, No.1, pp.45-52

Doi: 10.30812/adma.v2i1.1287

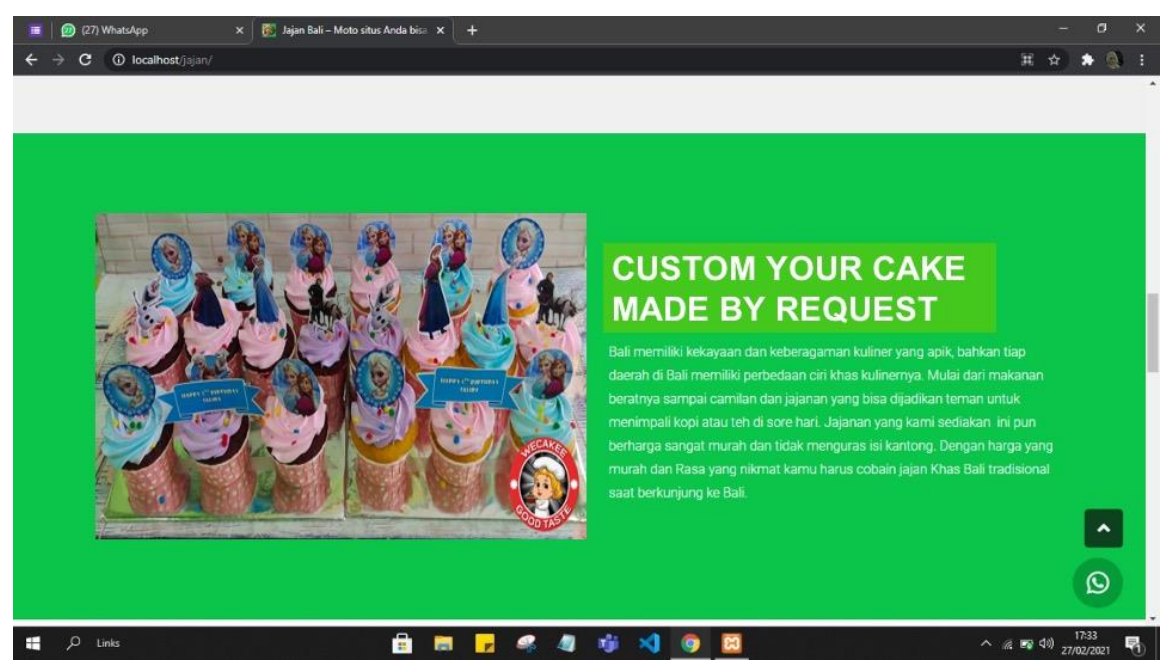

Gambar 4. Produk andalan Wecakee

Pada halaman ini dijelaskan produk andalan dari toko kue wecakee. Selain itu pada halaman ini juga dideskripsikan tentang custom cake yang dapat direquest oleh konsumen.

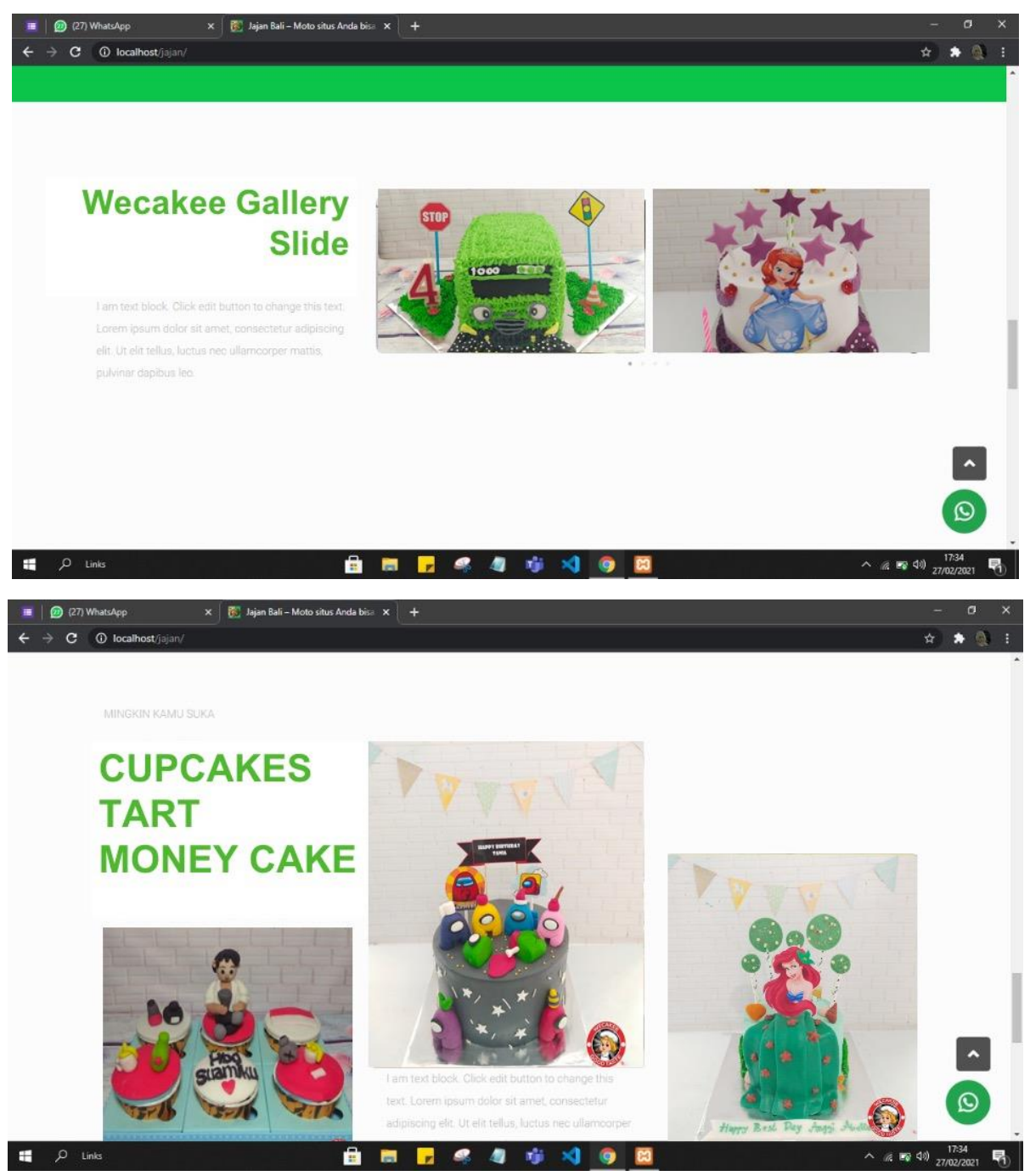

Gambar 5. Gallery Wecakee 
ADMA

Gurnal Pengabdian dan Pemberdayaan Masyarakat
Tahun, Vol.2, No.1, pp.45-52

Doi: $10.30812 / a d m a . v 2 i 1.1287$

Halaman ini merupakan halaman gallery produk wecakee. Disini akan ditampilkan produk-produk wecakee yang telah diproduksi dan dapat dipesan kembali oleh konsumen. Kedepannya pemilik dapat merubah tampilan website dan mengisi konten-konten website dengan produk-produk terbaru. Selanjutnya, website ini akan dihosting sehingga website ini dapat dilaunching kepada konsumen dan konsumen dapat mengakses website untuk mengetahui produk-produk wecakee yang ingin dipesan. Pelatihan penggunaan website dilakukan secara daring melalui aplikasi zoom. Melalui pelatihan ini, instruktur memaparan cara penggunaan website Toko Kue Wecakee.

Disamping melakukan pelatihan dan deskripsi penggunaan website, pemilik juga memberikan masukan atau saran perbaikan terhadap website sehingga website dapat lebih representatif dan dapat dilakukan pemasaran dengan lebih maksimal. Instruktur mengijinkan kepada pemilik Toko Kue Wecakee apabila ada fitur-fitur yang ingin ditambah sehingga saat ini website masih di-running pada localhost. Apabila fitur-fitur yang terdapat pada website Toko Kue Wecakee sudah disetujui oleh owner, maka website akan dihosting sehingga akan mudah diakses secara langsung oleh pemilik Toko Kue Wecakee. Pada Gambar 6. merupakan pelatihan penggunaan website yang dilakukan.

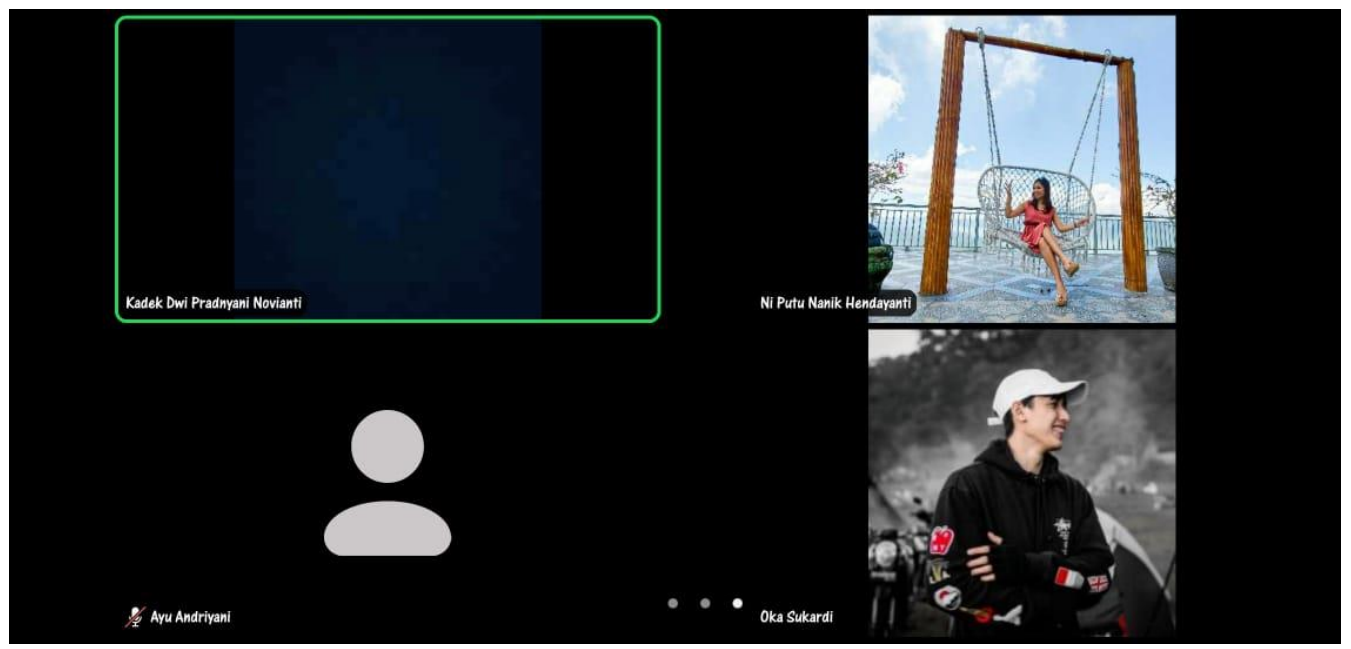

Gambar 6. Pelatihan website

4) Evaluasi Program

Evaluasi program pelatihan pemanfaatan website ini dilakukan setelah pelatihan berlangsung. Evaluasi dilakukan dengan menggunakan kuisioner yang dikirimkan melalui google form. Berikut merupakan link kuisioner yang dapat diisi oleh pemilik usaha Toko Kue Wecakee https://forms.gle/rVNVCwt6Naj1PG79A. Jadi hasil perhitungan kuisioner dengan skala likert dapat diperoleh kategori hasil evaluasi terkait pelaksanaan Program Pengabdian Masyarakat Pelatihan Pemanfaatan Website pada Toko Kue Wecakee tergolong Sangat Baik dengan nilai index $\mathbf{9 2 , 5 \%}$. 


\section{ADMA}

Jurnal Pengabdian dan Pemberdayaan Masyarakat
Tahun, Vol.2, No.1, pp.45-52

Doi: 10.30812/adma.v2i1.1287

\section{Kesimpulan}

Kesimpulan yang dapat diambil dari kegiatan pengabdian masyarakat pada usaha kue wecakee yaitu: dengan dibangunnya website Toko Kue Wecakee, mitra dapat melakukan pemasaran melalui website tersebut sehingga dapat memperluas wilayah pemasaran dan berdasarkan haisil evaluasi menggunakan kuisioner diperoleh hasil kategori sangat baik dengan nilai index sebesar $92,5 \%$.

\section{Ucapan Terima Kasih}

Ucapan terima kasih kami ucapkan kepada mitra yang sudah ikut berperan aktif dalam pelaksanaan kegiatan pengabdian masyarakat ini dan juga kepada ITB STIKOM Bali yang mendanai kegiatan pengabdian masyarakat ini.

\section{Daftar Pustaka}

A.K. Pranishita, "Pertumbuhan UMKM Bali Capai 4 Persen", Antara Bali, 18 Juni 2019. [Online]. Tersedia : https://bali.antaranews.com/berita/152191/pertumbuhan-umkm-bali-capai-4-persen [Diakses Tanggal 30 Oktober 2019].

Chaffey, Dave. (2000). Internet Marketing: Strategy, Implementation and Practice. New Jersey:Prentice Hall.

Kotler, Philip.,\& Amstrong Gary. 2012. Principles of Marketing. New Jersey : Person Education.

Nielsen J. (2003). Introduction to Usability. Diakses dari http://www.useit.com/alertbox/20030825.html

Rafi, Mohammed, Jaworski, B. J., Fisher, R. J., Paddison, G. J. (2003). Internet Marketing: Building Advantage in a Network Economy (2nd ed.). New York: McGraw-Hill Book. 